\title{
Technological Approaches to Reducing the Loss of Peat Raw Materials in Fields with Hydrological Regime
}

\author{
Eldar Abdollovich Kremcheyev* and Dinara Abdollovna Kremcheyeva \\ National Mineral Resources University, St. Petersburg, Russia; \\ kr.dinara@mail.ru
}

\begin{abstract}
Background/Objectives: Milling peat extraction technology is now the most wide-spread. It is urgent to reduce the in-process peat losses and decrease power consumption at the final stages of operating the fields with complicated hydrological regime. Methods/Statistical Analysis: While studying the process of peat spread dewatering after discharge from the edges of the ditch to the technological bed surface laboratory physical models were used. Physical simulation results after statistical processing of the data set (four parallel series of measurements for five height intervals within the dewatering time of 300 hours) were compared with the results obtained in the theoretical analysis based on the porous model of peat body. The regressive concordance coefficients foe the results obtained by the theoretical and physical models did not exceed 0.98. Findings: Based on the results of theoretical and experimental studies mathematical expressions are suggested for engineering calculations of technological parameters of the repair cycle during milled peat production in the fields with complicated hydrological regime. An innovative technology was proposed for repair of peat fields, enabling to increase the intensity of peat drying and extend cyclic peat harvesting with reduced area of technological sites. The theoretical data obtained and their engineering options proposed will provide increase in the extraction factor of onbalance peat reserves from 0.6 (for milling peat extraction technology) to 0.7-0.72. The proposed technology has significant environmental benefits, which is provided by concurrent field reclamation during milled peat production by growing the bog-forming plants on the ditch edges, which together with the reduction of greenhouse gas emissions provides intensified carbon dioxide absorption (up to 10 times) by the newly formed wetland ecosystem. Applications/Improvements: The proposed technology and developed engineering applications may be used by design institutions when drawing up plans for peat deposits extraction and developing abandoned and degraded peatland reclamation projects.
\end{abstract}

Keywords: Dehydration, Milled Peat, Peat, Production, Technology

\section{Introduction}

At present milling technology providing satisfactory peat production together with rational organizational approaches in a short production season is the most common scheme for peat production ${ }^{1-3}$. To implement the technological operations in peat harvesting it is necessary to carry out a set of preparatory activities at the initial stages of development of the field, including bog-preparatory operations for clearing of timber, drainage network construction and ditching, profiling bed surface. With the drawdown in the upper layers of the deposit, in order to maintain the required rate of drainage on the process area, the planned activities on the clearing and deepening of bed ditches are carried out. In the development of peat fields located below the intake water (lake, river) level, especially at the final stage, when the depth of the deposit layer entitled to drawdown becomes less than the minimum required drying rate, to provide technological conditions for peat drying and harvesting, the use of water pumping

${ }^{*}$ Author for correspondence 
stations is required to pump groundwater beyond the field through dikes, which increases energy consumption, and accordingly, the cost of finished peat products.

A major shortcoming of the harvesting method of peat deposit development is a reduction of the efficiency of field curing of milled peat on technological beds at values below the required drainage standards. At deposits with complicated hydrological regime this situation inevitably arises with the drawdown in the deposit layer. According to the technological design norms deepening of bed drains in the ground by more than 0.5 meters is unacceptable ${ }^{4}$, which leads to an ambiguous situation at the final stages of the deposit development. On the one hand the maintenance of the drainage network providing the required rate of drying is possible under the pressure dewatering (high energy consumption) or by deepening the drainage network, but this would lead to the drain deepening in the mineral soil more than by $0.5 \mathrm{~m}$ with a corresponding increase in the ash-contents of the developed layer by throwing out the mineral soil on the production field surface. On the other hand, it is possible to stop production with a corresponding peat losses and a decrease in the final production volume compared to the balance volume. In modern economic environment such significant technological peat losses are unacceptable, because basically, by the beginning of the present century, all peat fields in the Republic of Belarus, suitable for the industrial development, have been developed or are biosphere reserves.

In connection with the above mentioned, the purpose of this study is to intensify the milled peat production on the developed production areas and to reduce technological peat losses at the final stages of field development. The objective of the study is to reduce energy consumption in peat harvesting during peat field development with complicated hydrological regime.

\section{Concept Headings}

An assigned task is solved by the way when the milled peat harvesting in field development comprising the stages of timber clearing, drainage network construction and ditching, milled peat production, drainage network and production fields maintenance includes the additional stage in drainage network and production fields maintenance.

A schematic diagram of an additional process stage in drainage network and production fields maintenance is presented in Figure 1 - the plan of a process area for milled peat harvesting using tanker harvesters and the cross-section of a bed with bed ditches.

A process area for milled peat production on the upper deposit includes four production beds 1, divided lengthwise by bed ditches 2 and at front edges limited by ridge drains 3 . For the production machines movement bed ditches are connected in pairs by drains 4 , and one of them communicates with ridge drains by bridge crossings 5 . Strips for the milled peat stockpile formation 7 are reserved at the end of the process area 6 . An additional processing step in the drainage network and production fields maintenance is carried out by extracting a part of the peat deposit by strips 8 with the maximum depth of width to one fourths of the bed width along bed drains 2 by means of its equal spreading on the bed surface 1 and the subsequent surface profiling 9.

At the final stage, when the depth of the deposit layer entitled to drawdown becomes less than the minimum required drying rate, to provide technological conditions for peat drying and harvesting, during regular maintenance of the drainage network and production fields the extraction of a part of the peat deposit to a maximum depth by strips 8 of width to one-quarter of the bed width along bed drains 2 with its equal spreading on the bed surface and their subsequent profiling. As a result, the ground water level 10 before the process step as a consequence of deepening and broadening bed ditches reduces (level 11), and the rate of drying is retrieved due to an additional layer out of the extracted deposit on the bed surface.

Since the intensity of drawdown in the deposit layer on the strips 6 to form stockpiles 7 of milled peat is significantly less compared to the production beds 1 , there is no need in incrementing strips 6 by deposit extraction out of the adjacent strips along bed ditches 2 and ridge drains 3 .

\section{Theoretical Study}

In the process of reclamation of peat deposits according to the proposed scheme, water-logged peat raw material will be unloaded onto the surface of the peat field. Potentially, the average moisture of unloaded raw material may range in natural moisture of this type and kind of peat. It is obviously, that together with deposit reclamation according to the proposed technology, it is necessary to ensure operational moisture of the surface 

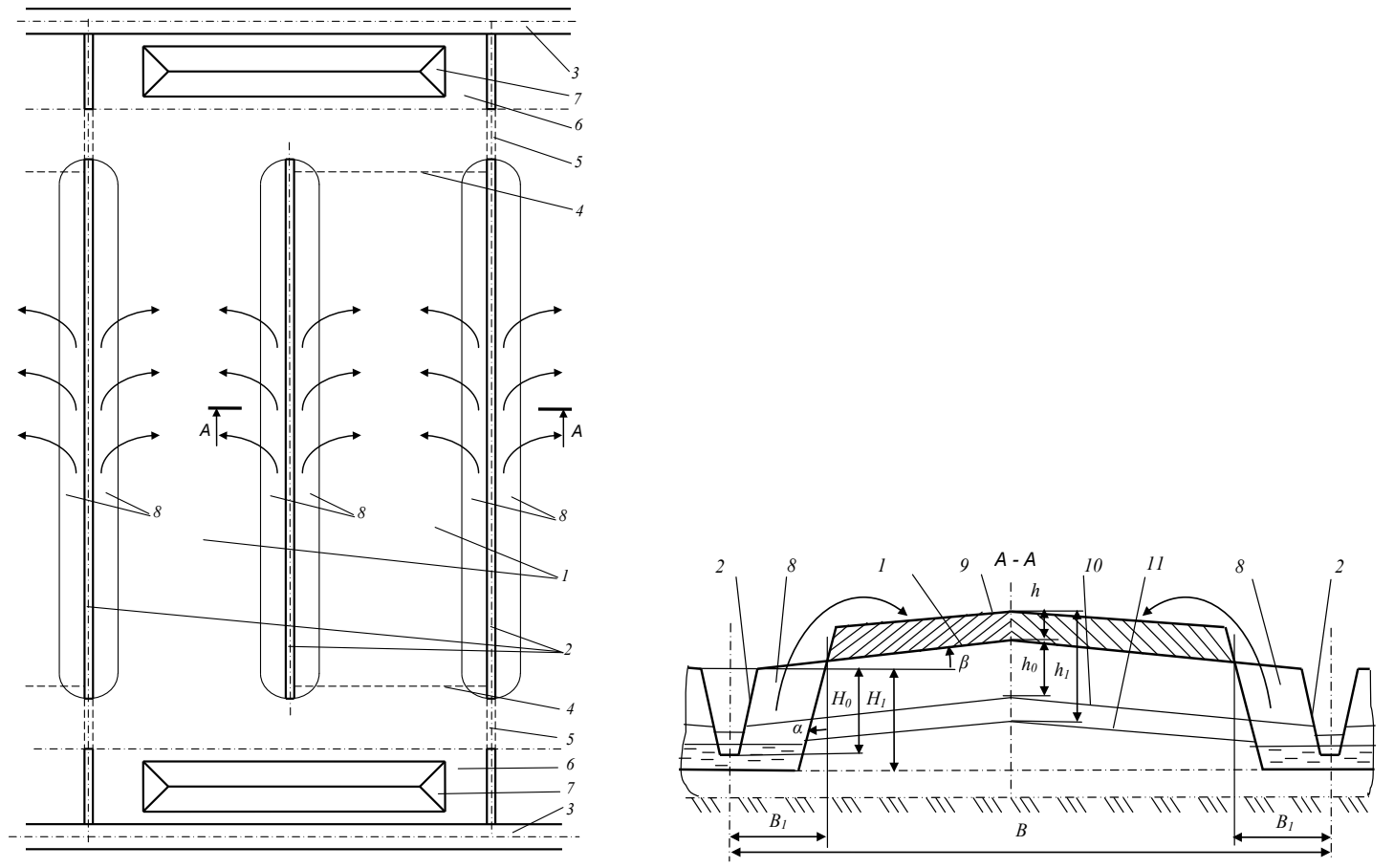

Figure 1. The plan of process area for milled peat production using tanker harvesters and the scheme to determine the overgrown layer height.

layer in order to perform the following harvesting operations in the current or future seasons. Peat raw materials being extracted from the field, changes from the two-phase state (liquid-solid) in the three-phase state (liquid-solid-gas), which determines a significant difference between the processes of moisture movement in an undisturbed deposit and the created peat layer. It is necessary to estimate the rational depth of the formed layer and the time required for reaching the equilibrium moisture content by it, at which the gravity moisture flow will equal to zero.

The conducted research showed that peat raw material is characterized by moisture suspension in the filtration equilibrium with equal capillary-osmotic and gravitational pressures in the dehydrated peat system, provided that the specific amount of moisture removed from the raw material before breaking filtration equilibrium increases with an increase in the height of the peat layer ${ }^{5,6}$. Primarily this phenomenon is explained by an increase in hydrostatic pressure in raw peat during dehydration in thicker layers. If compared with an artificial dehydration of peat, then to create the pressure of $2.0 \mathrm{MPa}(\omega=90 \div$ $80 \%)$ the required pile height would be about $200 \mathrm{~m}$ of water column ${ }^{6}$. At final moisture $\omega_{f n}<80 \%$ even higher compaction pressures are required due to the increase in the bonding energy of water with peat (Table 1 ). The more this bonding energy is, the less is $W$ and pore size (Table 2), which establishes the limits of dehydration periods: below $2.0 \mathrm{MPa}\left(\omega_{\text {init }}=90 \div 80 \%\right)$ and above $2.0 \mathrm{MPa}\left(\omega_{\text {fin }}<80 \%\right)$. The 1st period is gravitational dehydration, $\omega=(90 \div$ $93) \% \div(80 \div 84) \%$; the 2 nd period is the field or artificial drying, $\omega_{f i n}<(80 \div 84) \%$.

The condition of peat under which the capillary and gravity pressure values become equal is called critical in this study, in this case the critical state for different moisture values of peat raw materials is observed at different heights of the pile. At the critical state, the pile height is equal to the critical one for these conditions $h_{\text {pile }}=H_{\text {cr }}$. It is exactly at this critical state that the second stage of dewatering process commences, namely, the peat curing. It is specific that each value of $\omega$ is associated with the corresponding value of pore diameter (Table 2) and that of the pile height $h_{\text {pile }}$. Therefore, the height of the pile should be specified (taking into account Table 2 and Figure $2(a, b)$ ). The height of the pile, as a first approximation (without taking into 
Table 1. The form and the bonding energy of moisture with the solid phase of peat. Dehydration methods

\begin{tabular}{|c|c|c|c|c|c|}
\hline \multirow[b]{2}{*}{ The category of moisture } & \multirow[b]{2}{*}{ Notation } & \multirow{2}{*}{$\begin{array}{c}\text { Bonding energy } E, \\
\mathrm{~kJ} / \mathrm{mole}\end{array}$} & \multicolumn{2}{|c|}{ Water content } & \multirow{2}{*}{$\begin{array}{c}\text { Dehydration method } \\
\text { (variant) }\end{array}$} \\
\hline & & & $\begin{array}{l}W_{i}, \operatorname{kg}(\text { wet }) / \\
\operatorname{kg}(\text { dry })\end{array}$ & $\omega_{i}, \%$ & \\
\hline Chemically connected & $W_{c h}$ & $41.9-419$ & 0.04 & 3.84 & $(5)$ \\
\hline $\begin{array}{l}\text { Physically and chemically } \\
\text { connected }\end{array}$ & $W_{\text {phch }}$ & $21-63$ & 0.49 & 32.88 & $(5)(3)$ \\
\hline $\begin{array}{c}\text { Including adsorbed water } \\
\text { of monoabsorption }\end{array}$ & $W_{m}$ & $<63$ & 0.16 & 13.80 & (5) \\
\hline Osmotic & $W_{o s m}$ & $<2.1$ & 0.71 & 41.52 & $(3),(4)$ \\
\hline Mechanically holding water & $W_{\text {mech }}$ & - & 8.8 & 89.80 & $(1),(2),(3)$ \\
\hline \multicolumn{6}{|l|}{ Including: } \\
\hline capillary & $W_{c a p}$ & 0.84 & 6.75 & 87.10 & $(1),(2),(3)$ \\
\hline intracellular & $W_{i c e l}$ & - & \multirow{2}{*}{1.55} & \multirow{2}{*}{60.78} & \multirow{2}{*}{$(3),(5)$} \\
\hline immobilized & $W_{i m}$ & - & & & \\
\hline structurally captured & $W_{\text {str }}$ & - & 0.5 & 33.33 & $(3),(4)$ \\
\hline Total content & $W$ & - & 10 & 90.91 & $(1),(2),(3)$ \\
\hline
\end{tabular}

Note:

1. The gravitational (1): $\omega_{\text {init }}=(92 \div 93) \% \omega_{\text {fin }}=(87 \div 84) \%$.

2. Mechanical $(2): \omega_{\text {init }}=(87 \div 84) \%, \omega_{\text {fin }}=(65 \div 70) \%$.

3. Field drying $(3): \omega_{\text {init }}=(87 \div 84) \ldots(82 \div 84) \ldots(75 \div 79) \% \omega_{f i n}=(33 \div 40) \%$ (respectively for excavating, harvesting and milling methods of peat production).

4. Factory drying $(4): \omega_{\text {init }}=(40 \div 70) \%$, the final moisture is determined by the product type, the accepted factory method of processing peat raw materials and the way of moisture removing. For briquettes $\omega_{\text {fin }}=(15 \div 18) \%$; for tablets $\omega_{\text {fin }}=(12 \div 16) \%$; for pellets $\omega_{\text {fin }}=(8 \div 12) \%$; for sod peat (agglomerated in field and plant conditions) the moisture content $\omega_{\text {fin }} \leq 45 \%$; for milled peat the specified moisture content of $\omega_{s}=40 \%$.

5. The thermal drying.

account moisture evaporation), is determined by the equation as follows:

$h_{\text {pile }}=\frac{2 \sigma \cdot \cos \Theta}{\rho \cdot g \cdot r}$, where $\sigma$ is the surface tension coefficient, $\mathrm{H} / \mathrm{m} ; r$ is the pore radius, $\mathrm{m} ; \Theta$ is the angle of the hard phase contact with liquid, degree; $g$ is the gravity acceleration, $\mathrm{m} / \mathrm{s}^{2} ; \rho_{\text {liq }}$ is the density of the inherent moisture, $\mathrm{kg} / \mathrm{m}^{3}$.

Table 2. Dependence of the peat pile height on average pore size

\begin{tabular}{|c|c|c|c|c|c|}
\hline $\begin{array}{c}\text { Pore diameter } \\
\mathbf{D} \cdot \mathbf{1 0}^{\mathbf{6}}, \mathbf{m}\end{array}$ & $\begin{array}{c}\text { The bonding energy of } \\
\text { moisture E, } \mathbf{k J} / \mathbf{m o l e}\end{array}$ & $\begin{array}{c}\text { Moisture type, } \mathbf{W}, \mathbf{k g}(\text { wet }) / \\
\mathbf{k g}(\mathbf{d r y})\end{array}$ & \multicolumn{3}{|c|}{ The peat pile height at average pore size, $\mathbf{m}$} \\
\cline { 3 - 6 } & 0.44 & $W_{\text {icel }}$ & Maximum & Most likely & Minimum \\
\hline 12.0 & 0.88 & $W_{\text {cap }}$ & - & 4.96 & - \\
\hline 6.0 & 0.10 & $W_{\text {mech }}$ & 0.3 & - & - \\
\hline 50.0 & 0.21 & $W_{\text {im }}$ & 0.6 & - & - \\
\hline 25.0 & 5.84 & $W_{\text {osm }}$ & & - & 10.90 \\
\hline 0.9 & 10.51 & $W_{\text {phch }}$ & & - & 29.76 \\
\hline 0.5 & & & & & - \\
\hline
\end{tabular}

Note:

1. $T=293 \mathrm{~K}, \sigma=73 \cdot 10^{-3} \mathrm{~N} / \mathrm{m}, g=9.81 \mathrm{~m} / \mathrm{s}^{2}, \Theta=0^{0} ; \operatorname{Cos} \Theta=1$, upper type peat;

2. $\mathrm{E}=2 \sigma \cdot \operatorname{Cos} \Theta \cdot V_{l i q} / r, V_{l i q}=m / \rho_{l i q} ; 3$. $W_{\star}$ is moisture naming (Table 2$) ; 4$. Effective size of pores at $\phi \approx 0.7$ amounts to $D_{e f}=56 \cdot 10^{-10} \mathrm{~m}$. 

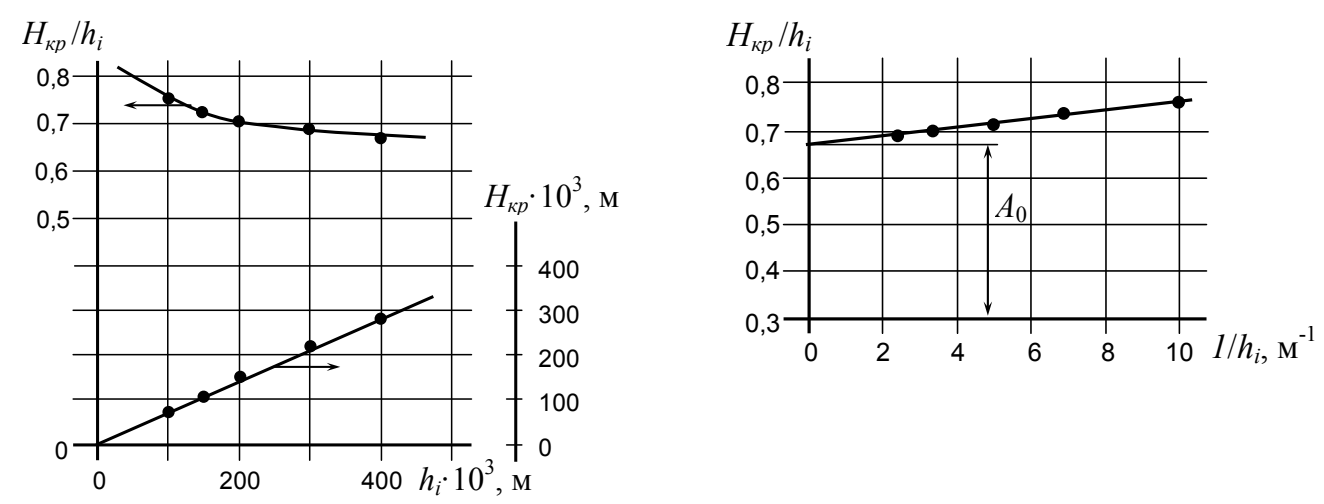

Figure 2. Relationships: a $-H_{\mathrm{cr}} / h_{\mathrm{i}}=f\left(h_{\mathrm{i}}\right) ; \sigma-H_{\mathrm{cr}} / h_{\mathrm{i}}=f\left(1 / h_{\mathrm{i}}\right)$ for high-moor Eriophorum-Sphagnum peat, $R_{\mathrm{T}}=(20 \div 25) \%$.

Values $h_{\text {pile }}$ for different groups of the peat pore volume (the maximum, the most probable, the minimum), are shown in Table 2. Values $h_{\text {pile }}$ are compared taking into account the type of the moisture content (according to Table 1) and the bonding energy of moisture with the solid phase of peat for different sizes of pores. Thus, for the most probable average sizes of the pores, the height of the peat pile changes from 2.48 to $4.96 \mathrm{~m}$, which can be done technologically by a wide range of excavationhandling and loading machinery employed by the peat industry; however, as to ensuring the operability of the machinery in the current production season, it seems advisable to select the thickness of the reclaimed layer in the range of 0.3-0.6 m, obtaining the critical spreading thickness of 0.21-0.42 m.

Reclaiming the peat fields applying the suggested technological process is possible both during the production season and within the off-season periods ${ }^{7}$. If the fields are reclaimed during the period of the limited moisture evaporation (October-March) the thickness of the reclaimed layer reaches its critical value independently of the amount of the received solar radiation and the intensity of evaporation. For example, for the peat layer of 0.4 $\mathrm{m}$, the time for achieving the critical height and moisture content (Scheuchzeria-Sphagnum peat, $\mathrm{R}_{\mathrm{T}}=(22 \ldots 25) \%$, $H_{\mathrm{cr}}=0.273 \mathrm{~m}$, at $\left.W_{\mathrm{cr}}=9.75 \mathrm{~kg}(\mathrm{w}) / \mathrm{kg}(\mathrm{d})\right)$ makes 232 hours.

The function of evaporation in the process of peat dewatering is not significant at the first stage (gravitation period $h_{\text {pile }}>H_{\text {cr }}$ ), but is crucial for the second stage $\left(h_{\text {pile }} \leq H_{\text {cr }}\right)$.

While studying the process of dewatering the peat spread from the edges of the ditch during the production season, the idea of equilibrium time $\tau_{\mathrm{e}}$ have been introduced in this study reflecting the period required for the peat to achieve the condition under which the flow of the evaporation moisture becomes equal to the gravitational flow. This can be explained by the fact that the lower the initial height of the pile and the higher the thermal flow at the height lower than the critical one is, the earlier the evaporation from the pile surface should be taken into account. At $\tau=\tau_{\mathrm{e}}$ the evaporation intensity is equal to the intensity of the gravitational dewatering, but at very low values of the evaporation intensity, which contribution to the total flow of moisture is insignificant at the preset values of the initial layer thickness, it can be ignored at $\tau<\tau_{\mathrm{e}}$. At low values of dewatering intensity the contribution of the evaporation intensity becomes more significant and it should necessarily be taken into account at $\tau>\tau_{\mathrm{e}}$, i.e. when the thickness of the layer tends to the critical value for preset characteristics of the peat raw materials. As the current height of the pile becomes equal to the critical height, the function of the gravitational flow intensity is excluded from the overall moisture balance, and the total intensity of dewatering can be considered equal to the evaporation intensity.

Thus, the gravitational dewatering of a peat pile is a predetermining factor up to $h_{\mathrm{i}}>H_{\mathrm{cr}}$ as compared to moisture evaporation from the pile surface, increasing as the temperature and the radiation balance $\left(q_{1}=B\right)$ grow and as the relative air humidity decreases. It has been assumed that the end point for taking evaporation into account in the suggested technological process of the production season reclaiming is represented by time of equilibrium (equilibrium time) $\tau_{\mathrm{e}}$, when the value of gravitational dewatering intensity and the evaporation value become equal, i.e. when evaporation accounts for $50 \%$ of the total moisture flow. 


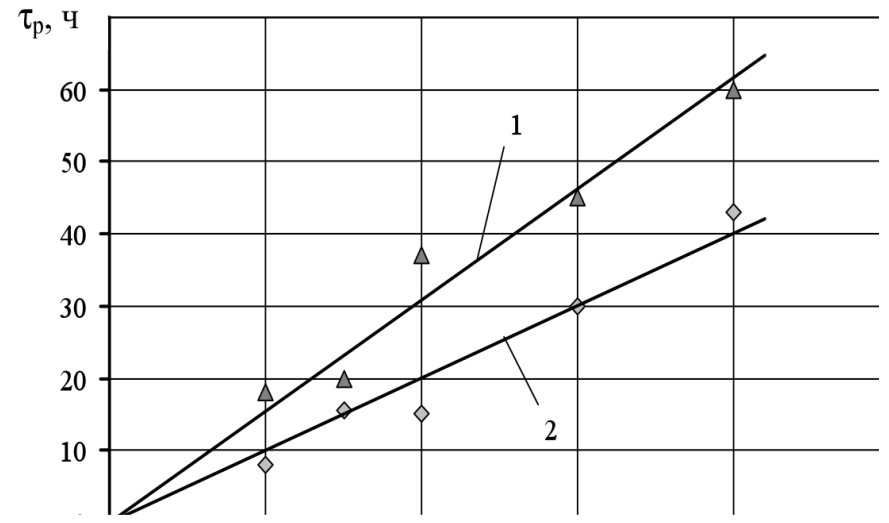

Figure 3. Relationship between the equilibrium time of dewatering Scheuchzeria-Sphagnum peat with the degree of decomposition of $22 \ldots 25 \%$ (allowing for the gravitational flow of moisture and evaporation) and the initial layer thickness (convective heat input -1 , radiative-convective heat input -2 ) $\tau_{\mathrm{p} i}=k_{h i} \cdot \mathrm{h}_{\text {init }}, k_{h 1}=0.15 \cdot 10^{3} \mathrm{~h} / \mathrm{m}, k_{h 2}=0.1 \cdot 10^{3} \mathrm{~h} / \mathrm{m}$.

The time to achieve the state of equilibrium is described by the linear relationship as follows (Figure 3):

$\tau_{\mathrm{e}}=k_{h} \cdot h_{H}$,

With angular coefficient $k_{h i}=d \tau_{\mathrm{e}} / d \mathrm{~h}_{\mathrm{p}}, \mathrm{h} / \mathrm{m}$, with the value of $k_{h i}=0.15 \cdot 10^{3} \mathrm{~h} / \mathrm{m}$.

The obtained data suggest that the developed theoretical approaches could be recommended for selecting the rational thickness parameters of the peat material layer that is reclaimed onto the deposit surface while realizing the proposed technological pattern.

\section{Discussion}

\subsection{Engineering Application}

Engineering analysis for implementing the developed technological approaches makes it possible to determine the required width of processing the edges of the ditch based on the required thickness of the layer (when the fields are reclaimed in the off-season periods), or based on the time required to achieve the equilibrium time.

Height $h_{\mathrm{b}}$ of the built-up layer is determined on the basis of the excavated deposit volume. It depends on depth PILE ${ }_{1}$ and width $\mathrm{B}_{1}$ of the processed edge of the ditch, i.e. $h=f\left(H_{1}, B_{1}\right)$. Given the equality of the crosssection areas of the excavated and the built-up layers of the peat deposit $S_{\mathrm{e}}=S_{\mathrm{b}}$ taking into account the standard parameters of the bed ditch, as well as the profile of the bed, the planned height $h$ of the built-up layer is equal to:

$h_{\mathrm{b}}=\frac{2 B_{1} H_{1} \cos \alpha-\frac{b_{0}+b_{1}}{2} H_{0}+\left(\frac{B_{1}-b_{1}}{2}\right)^{2} \operatorname{tg} \beta}{2\left(\frac{B}{2}-B_{1}\right)}$

where $H_{1}$ and $B_{1}$ are the depth and the width of the edge of the ditch for deposit excavation; $\alpha$ is the rate of slope in the bed ditch (the relative value of the rate of slope in the bed ditches of peat deposit equals to 0,25$) ; H_{0}$ and $b_{0}$ are the depth of the ditch and the bottom width $\left(H_{0}=1.8 \ldots 2.0 \mathrm{~m} ; b_{0}\right.$ $=0.3 \mathrm{~m}) ; b_{1}=b_{0}+0.5 H_{0}$ is the width of the ditch at the level of the bed surface; $B$ is the distance between the axes of the adjoining bed ditches (for the upper deposits $B=20 \mathrm{~m}$; for the lower deposits $B=40 \mathrm{~m}$ ); $h_{0}$ and $h_{1}$ are the dewatering norms before and after the deposit excavation activity; $\beta=$ $5^{0}$ is the bank angle of the technological bed surface;

or

$$
\tau_{\mathrm{e}}=k_{h}\left(\frac{2 B_{1} H_{1} \cos \alpha-\frac{b_{0}+b_{1}}{2} H_{0}+\left(\frac{B_{1}-b_{1}}{2}\right)^{2} \operatorname{tg} \beta}{B-2 B_{1}}\right) .
$$

The planned processing of the deposit layer in a production season amounts to $300 \mathrm{~mm}$ (at average milling depth of $h_{\mathrm{m}}=11 \mathrm{~mm}$ and with the number of cycles of $z=25$ ). Therefore, for example, to achieve the height of the built-up layer of $h_{\mathrm{b}}=0.9 \mathrm{~m}$ the edges of the ditch with the width of $\mathrm{B}_{1}=2.5 \mathrm{~m}$ should be processed at the upper deposit.

Given the decrease in the areas of the technological fields, it is still possible to preserve the milling peat production figures every season by means of increasing the milling depth $h_{\mathrm{m}}$, as in this case the curing of the granulated peat would be more intensive as a result of the increased norm of dewatering $h_{1}$ and due to the aeration of the spread materials. Moreover, the milled peat, produced out of the built-up layers, will possess higher density because of the higher degree of decomposition in the deep-layer deposits.

\subsection{Technical Application}

Deposit excavation activities can be implemented by the peat single-bucket excavators with the bucket capacity up to $1 \mathrm{~m}^{3}$ or by the continuous bucket excavators equipped 


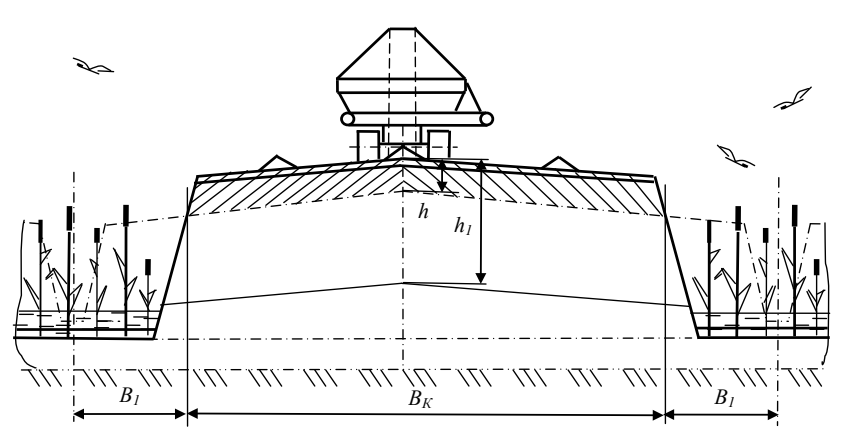

Figure 4. Milling peat production on beds with builtup layer from the excavated deposit and simultaneous cultivation of bog-forming.

with special operating tools installed on the rotary platform and featuring the multi-bucket frame combined with a belt conveyer ${ }^{8,9}$.

The activities for increasing the surface of the beds can be done stage by stage excavating the deposit by narrower strips; however, the width $B_{K}$ of the process area should correspond to the operational parameters of the machines employed for the basic operations in the milled peat production, i.e. milling cutters, agitator rakes, swath collectors and hopper-type harvesting tractor units.

The advantage of this method is that the production of the milled peat in the technological beds with the built-up layers can be implemented simultaneously with growing the bog-forming plants on the edges of the ditch (Figure 4). It mitigates the negative impact produced on the environment by the continuous industrial development of the deposit and facilitates the process of rehabilitating the natural landscape.

\section{Conclusion}

The results of theoretical and experimental investigations showed that the complex activities on reclamation of the drainage network and the production fields by means of extracting a part of the peat deposit by strips with the maximum depth and with the width up to one fourth of the bed width in parallel to the bed ditches and by means of equal spreading of the extracted peat on the bed surface will improve the efficiency of operational equipment and decrease specific energy consumption in the process using harvesting method in peat production at the final stage of the peat deposit development. The whole complex of activities in the company could be implemented with the available fleet of the machinery and mechanisms and would not require any extra investments in purchasing or upgrading the equipment.

\section{References}

1. Antonov VY, Kopenkin VD. Technology and comprehensive mechanization of peat production. Textbook. Guidebook for high schools. 2nd edn, Moscow: Nedra, 1983.

2. Lazarev AV, Korchunov SS. Peat Reference Book: Moscow: Nedra, 1982.

3. Joosten H, Clarke D. Wise use of mires and peatlands. Available from: http://www.peatsociety.org/sites/default/ files/files/wiseusetakko.ppt. Date accessed: 05/09/2015.

4. Industry-Specific Process Engineering Standard. 19-86 (RSFSR Ministry of Fuel Industry). Norms of operating design of companies engaged in peat production. Moscow: Mintopprom RSFSR, 1986.

5. Kremcheyev YA, Afanasyev AY, Yefremov AS. Gravitational dehydration of peat raw pile with evaporation of moisture. Mining Informational and Analytical Bulletin (Scientific and Technical Journal): Moscow: Gornaya Kniga. 2013; 3:93-103.

6. Kremcheyev YA, Afanasyev AY. Estimation of efficiency of gravitational dehydration of raw materials with complex integrated mechanization of all-year peat production. Mining Informational and Analytical Bulletin (Scientific and Technical Journal): Moscow: Gornaya Kniga. 2012; 4:50-8.

7. Goryachev V. The artificial dehydration of peat. Monograph: Tver: TSTU, 2012.

8. Basalay GA. Method of peat deposit development. Patent for Invention (IPC E21S 49/00) No 13072 of 05.01.2010.

9. Basalay GA, Yaskel AA. Peat extracting excavator. Patent for the utility model (IPC E21S 49/00) No 4974 of 15.10.2008. 